\title{
Canagliflozin-associated Diabetic Ketoacidosis with Lower-than-anticipated Glucose Levels
}

\author{
Sonali Vadi, Manjusha Agarwal' \\ Departments of Critical Care Medicine and 'Internal Medicine, Gleneagles Global Hospitals, Mumbai, Maharashtra, India
}

\section{Abstract}

The Food and Drug Administration has approved the use of sodium-glucose co-transporter 2 (SGLT-2) inhibitors for use in Type II diabetics. These are a relatively new addition to the armamentaria of diabetes management. Postmarketing surveillance is a witness to several side effects, a morbid one being ketoacidosis. Herein is discussed a scenario of a Type II diabetic who presented with substantial ketoacidosis without significant hyperglycemia. The absence of the customary precipitating factors and the presence of a recent introduction of canagliflozin, a SGLT-2 inhibitor to the diabetes prescription, hinted at the causal relationship. Of note, she had never experienced diabetic ketoacidosis in the past prior to commencement of SGLT-2 inhibitor therapy. As clinicians, we need to be aware of the treatment-emergent adverse effect of this relatively new class of diabetic treatment.

Keywords: Canagliflozin, diabetic ketoacidosis with lower-than-anticipated glucose levels, euglycemic diabetic ketoacidosis, sodium-glucose co-transporter 2 inhibitors

\section{INTRODUCTION}

As clinicians, we need to be aware that medications used for disease management can paradoxically induce effects, causing an already sick patient to become worse. Sodium-glucose co-transporter 2 (SGLT-2) inhibitors, a fairly recent addition to the pool of diabetes medications, are associated with a variety of side effects, the fatal one being ketoacidosis. This adverse effect reported in the postmarketing surveillance significantly adds to the morbidity of illness. Herein is discussed this treatment-emergent adverse effect that clinicians need to be aware of.

\section{Case Report}

A middle aged lady presented to the emergency room with nausea and emesis for 4 days, fever for 2 days, and malaise. Her medical comorbidities included Type II diabetes, hypertension, and hypothyroidism. Her body mass index was $22.3 \mathrm{~kg} / \mathrm{m}^{2}$. Hospitalized a month ago for community-acquired pneumonia, she was discharged on a combination of glimepiride-metformin, teneligliptin, human actrapid insulin, and canagliflozin as an add-on. Her serum glycosylated hemoglobin levels were at $11.1 \%$ then. At a follow-up 15 days later following an improvement in her glucose control, insulin was discontinued.

\begin{tabular}{|l|l|}
\hline \multicolumn{3}{c|}{ Access this article online } \\
\hline Quick Response Code: & Website: \\
& www.ijccm.org \\
\hline
\end{tabular}

Initially admitted to the floors with the said complaints, she was later transferred to the Intensive Care Unit following severe metabolic acidosis with serum bicarbonate levels at $3.3 \mathrm{mmol} / \mathrm{L}$ and $\mathrm{pH}$ at 6.89 on her arterial blood gas. She complained of dryness of mouth and was very thirsty. Clinically dehydrated, she was administered intravenous fluids. Other medications included intravenous sodium bicarbonate, human actrapid insulin infusion titrated as per the glucose levels, and symptomatic treatment for her gastrointestinal symptoms. Severe metabolic acidosis without very high serum glucose levels and the contemporaneous existence of canagliflozin raised the suspicion of diabetic ketoacidosis (DKA) with lower-than-anticipated glucose levels. Table 1 shows the acid-base results while Table 2 depicts the fingerstick glucose levels on the day of presentation. Meanwhile, other laboratory results returned as normal complete blood count, blood urea nitrogen at $12 \mathrm{mg} / \mathrm{dl}$ (normal: 9.8-20.1 mg/dl), serum creatinine at $1.4 \mathrm{mg} / \mathrm{dl}$ (normal: $0.57-1.11 \mathrm{mg} / \mathrm{dl}$ ), serum D3-Hydroxybutyrate

Address for correspondence: Dr. Sonali Vadi, Gleneagles Global Hospital, 35 E. Borges Road, Parel, Mumbai - 400 012, Maharashtra, India. E-mail: sonalivadi@hotmail.com

This is an open access article distributed under the terms of the Creative Commons Attribution-NonCommercial-ShareAlike 3.0 License, which allows others to remix, tweak, and build upon the work non-commercially, as long as the author is credited and the new creations are licensed under the identical terms.

For reprints contact: reprints@medknow.com

How to cite this article: Vadi S, Agarwal M. Canagliflozin-associated diabetic ketoacidosis with lower-than-anticipated glucose levels. Indian J Crit Care Med 2017;21:793-5. 
Vadi and Agarwal: Canagliflozin-associated DKA with lower-than-anticipated glucose

\begin{tabular}{|c|c|c|c|c|c|c|}
\hline Time & Location & $\mathrm{pH}$ & $\mathrm{PaCO}_{2}(\mathrm{mmHg})$ & $\mathrm{PaO}_{2}(\mathrm{mmHg})$ & $\mathrm{HCO}_{3}{ }^{-}(\mathrm{mmol} / \mathrm{L})$ & Lactate $(\mathrm{mmol} / \mathrm{L})$ \\
\hline 0044 & Floors & 6.89 & 17.2 & 56.3 & 3.3 & 1.35 \\
\hline 0236 & $\mathrm{ICU}$ & 7.08 & 18.3 & 160.1 & 5.5 & 1.08 \\
\hline 0908 & $\mathrm{ICU}$ & 7.17 & 13.1 & 150.3 & 4.8 & 0.59 \\
\hline 1612 & $\mathrm{ICU}$ & 7.37 & 25.8 & 112 & 14.7 & 0.6 \\
\hline
\end{tabular}

ICU: Intensive Care Unit

\begin{tabular}{|c|c|c|c|c|c|c|c|c|c|c|c|c|c|}
\hline Time & 0200 & 0400 & 0500 & 0600 & 0700 & 0800 & 1000 & 1200 & 1400 & 1600 & 1800 & 2000 & 2200 \\
\hline Fingerstick glucose levels (mg/dl) & 215 & 240 & 295 & 205 & 109 & 150 & 161 & 174 & 140 & 146 & 152 & 169 & 199 \\
\hline
\end{tabular}

at $11.79 \mathrm{mmol} / \mathrm{L}$ (normal: $0.02-0.27 \mathrm{mmol} / \mathrm{L}$ ), serum potassium at $6.0 \mathrm{mEq} / \mathrm{L}$ (without simultaneous electrocardiogram changes), anion gap: 24, measured serum osmolality: $330 \mathrm{mOsm} / \mathrm{kg}$ (normal: 275-300 $\mathrm{mOsm} / \mathrm{kg}$ ), and serum glycosylated hemoglobin levels at $11.1 \%$. Calculated serum osmolality was 306 with osmolar gap of $24 \mathrm{mOsm} / \mathrm{kg}$. Ultrasound of her abdomen was nonrevelatory.

Clinical recovery was evident within the following $24 \mathrm{~h}$ with an improvement of acidosis and stabilization of serum glucose levels. Seventy-two hours later, she was transferred back to the floors and later discharged on oral hypoglycemic agents without canagliflozin. At 6-month follow-up, her serum glucose levels have remained well under control without any further episodes of euglycemic DKA.

\section{Discussion}

Approved by the Food and Drug Administration (FDA) and released for use in 2013, SGLT-2 inhibitor canagliflozin acts by blocking glucose reabsorption in the proximal renal tubules with a resultant glycosuria. ${ }^{[1]}$ Pancreas decreases its insulin secretion following a reduction in blood glucose. Ensuing increased glucagon-to-insulin ratio ${ }^{[2]}$ leads to gluconeogenesis, ketogenesis, ${ }^{[3]}$ and a consequent ketoacidosis. ${ }^{[4,5]}$ In the same vein, these effects are pronounced following a reduction in insulin intake. ${ }^{[6]}$ On the other hand, given the inhibition of glucose reabsorption at the renal tubular level, an advantage of this group of medication is that the occurrence of hyperglycemia is moderated without consequent hypoglycemia. ${ }^{[7]}$ This combination of ketoacidosis without significantly elevated serum glucose levels is euglycemic DKA with lower-than-anticipated glucose levels. ${ }^{[8]}$ Postmarketing surveillance has seen the occurrence of DKA following the use of canagliflozin. The FDA issued a warning in May 2015 about SGLT-2 inhibitors leading to ketoacidosis ${ }^{[9]}$ that was updated in December 2015. Reported triggers for occurrence of ketoacidosis in patients on SGLT-2 inhibitors include acute illness, sepsis, recent surgery, starvation, decrease in carbohydrate intake, decrease in insulin intake, and significant changes in the level of physical activity, or pregnancy. ${ }^{[6,10]}$

Given her symptomatic presentation with nausea, emesis, and feeling thirsty with a background of uncontrolled blood glucose levels, a diagnosis of DKA was entertained. However, severe acidosis with high serum D3-Hydroxybutyrate levels and modestly elevated serum glucose levels in the presence of a SGLT-2 inhibitor prescription led to the diagnosis of DKA with lower-than-anticipated glucose levels. Given a satisfactory glycemic control about 2 weeks later and to prevent the occurrence of hypoglycemia, insulin was discontinued. This stoppage of insulin was the likely trigger factor for DKA with lower-than-anticipated glucose levels in the scenario. She was managed on the lines of a standard DKA protocol. ${ }^{[8]}$ Of note, she had never been hospitalized in the past for DKA prior to commencing SGLT-2 inhibitor.

Thus, ketoacidosis in the absence of marked hyperglycemia should alert an astute physician about DKA with lower-than-anticipated glucose levels in a diabetic on a SGLT-2 inhibitor prescription. Additionally, it would be prudent to add SGLT-2 inhibitors to the existent list of etiologies for DKA with lower-than-anticipated glucose levels.

\section{ConcLusion}

On the spectrum of DKA lies DKA with lower-than-anticipated glucose levels that is characterized by ketoacidosis without significant hyperglycemia. The discussed scenario highlights the significance of the existence of an ominous off-shoot of SGLT-2 inhibitors, DKA with lower-than-anticipated glucose levels, the occurrence of which can be possibly predicted by urine or serum ketone testing in symptomatic individuals despite the absence of significant hyperglycemia. As clinicians, we need to be aware about this life-threatening treatment-emergent adverse effect of SGLT-2 inhibitors which have recently been added to the armamentarium of diabetes management.

\section{Financial support and sponsorship} Nil.

\section{Conflicts of interest}

There are no conflicts of interest.

\section{References}

1. Tahrani AA, Barnett AH, Bailey CJ. SGLT inhibitors in management of diabetes. Lancet Diabetes Endocrinol 2013;1:140-51. 
2. Ferrannini E, Muscelli E, Frascerra S, Baldi S, Mari A, Heise T, et al. Metabolic response to sodium-glucose cotransporter 2 inhibition in type 2 diabetic patients. J Clin Invest 2014;124:499-508.

3. Keller U, Schnell H, Sonnenberg GE, Gerber PP, Stauffacher W. Role of glucagon in enhancing ketone body production in ketotic diabetic man. Diabetes 1983;32:387-91.

4. Ogawa W, Sakaguchi K. Euglycemic diabetic ketoacidosis induced by SGLT2 inhibitors: Possible mechanism and contributing factors. J Diabetes Investig 2016;7:135-8.

5. Taylor SI, Blau JE, Rother KI. SGLT2 inhibitors may predispose to ketoacidosis. J Clin Endocrinol Metab 2015;100:2849-52.

6. Rosenstock J, Ferrannini E. Euglycemic diabetic ketoacidosis: A predictable, detectable, and preventable safety concern with SGLT2 inhibitors. Diabetes Care 2015;38:1638-42.

7. Chao EC. SGLT-2 inhibitors: A new mechanism for Glycemic control.
Clin Diabetes 2014;32:4-11

8. Handelsman Y, Henry RR, Bloomgarden ZT, Dagogo-Jack S, DeFronzo RA, Einhorn D, et al. American association of clinical endocrinologists and American college of endocrinology position statement on the association of sglt-2 inhibitors and diabetic ketoacidosis. Endocr Pract 2016;22:753-62.

9. US Food and Drug Administration. FDA Drug Safety Communication: FDA Warns that SGLT2 Inhibitors for Diabetes May Result in a Serious Condition of too Much Acid in the Blood. Available from: http:/ www.fda.gov/drugs/drugsafety/ucm446845.htm. [Last accessed on 2015 May 15].

10. Peters AL, Buschur EO, Buse JB, Cohan P, Diner JC, Hirsch IB, et al. Euglycemic diabetic ketoacidosis: A potential complication of treatment with sodium-glucose cotransporter 2 inhibition. Diabetes Care $2015 ; 38: 1687-93$ 